\title{
A review of the One Health concept and its application as a tool for policy-makers
}

\author{
Rodrigo de Macedo Couto1 (iD and Daniel Friguglietti Brandespim² (D)
}

1. Department of Epidemiology, Faculdade de Saúde Pública, Universidade de São Paulo (USP), São Paulo/SP, 04024-002, Brazil; 2. Departament of Veterinary Medicine, Universidade Federal Rural de Pernambuco (UFRPE), Recife/PE, 52171-900, Brazil.

Corresponding author: Rodrigo de Macedo Couto, e-mail: rodrigoscouto@hotmail.com Co-author: DFB: danielbrandespim@gmail.com

Received: 22-02-2020, Accepted: 15-05-2020, Published online: 24-06-2020

doi: www.doi.org/10.14202/IJOH.2020.83-89 How to cite this article: de Macedo Couto R, Brandespim DF (2020) A review of the One Health concept and its application as a tool for policy-makers, Int. J. One Health, 6(1): 83-89.

\begin{abstract}
The One Health concept represents the inseparability of human, animal, and environmental health through a unified view of health care. This article addressed the topic of public health policies from the One Health perspective, demonstrating its inclusion in various health agendas such as emerging and reemerging infectious diseases, basic sanitation, mental health, chronic non-communicable diseases, interpersonal violence, and food safety. The results showed that the application of the One Health concept to the development and implementation of policies is associated with a growing need to involve transdisciplinary teams for solving complex problems to improve communication and to ensure the relevance and acceptability of public policies, thus guaranteeing governance. According to the principle of efficiency, the government must be aware of the evolution of technical knowledge and should use the One Health approach to improve the efficacy of already existing systems. We, therefore, conducted this review to contextualize current knowledge in this topic which is becoming an essential tool for public health policy-makers and practitioners around the world promoting a reflection on the importance of multiprofessional articulation in the implementation of intersectoral public health policies.
\end{abstract}

Keywords: One Health, public administration, public health, public health policies, sustainability.

\section{Introduction}

Across the globe, we experience the rapid movement of individuals and products, an increasing demand for protein sources, habitat destruction, increased contact between humans and animals, climate change, and growing antimicrobial resistance, among other challenges that directly or indirectly influence health [1]. In 2008, the World Health Organization (WHO), the World Organization for Animal Health (OIE), and the Food and Agricultural Organization of the United Nations launched an initiative called "One World, One Health," in which the term "One Health" was a concept suggested to demonstrate the inseparability of human, animal, and environmental health [2]. In addition, the United Nations recently stressed that intersectoral and multidisciplinary measures and a unified view of health care are critical to achieving the goals of the 2030 Agenda for Sustainable Development [3].

Few public health policies comprise all pillars of the One Health approach to prevent diseases and to protect and promote health by joining efforts from different sectors through multidisciplinary collaboration and by recognizing the interdependence between

Copyright: Couto and Brandespim. This article is an open access article distributed under the terms of the Creative Commons Attribution 4.0 International License (http://creativecommons.org/ licenses/ by/4.0/), which permits unrestricted use, distribution, and reproduction in any medium, provided you give appropriate credit to the original author(s) and the source, provide a link to the Creative Commons license, and indicate if changes were made. The Creative Commons Public Domain Dedication waiver (http:// creativecommons.org/ publicdomain/zero/1.0/) applies to the data made available in this article, unless otherwise stated. the different components of the human/animal/environment triad. Little importance is given to the institutional, political, and social factors associated with the implementation of these public policies within the One Health approach [4].

In view of the new challenges of the millennium, this article aims to address a review of the One Health concept, which is becoming an essential knowledge tool for public health policy-makers who seek strategies for more efficient public administration and better governance.

\section{Concept and Foundations of One Health}

One Health is a scientifically established and validated concept of great social importance that initially emerged from the integrated study of zoonoses $[4,5]$. It currently encompasses the interconnections between human, animal, and environmental health in a multidisciplinary approach represented by a complex biological and social system, which involves multiple actors and processes and their interactions overtime at the local, national, and global level [6]. Figure-1 summarizes the main findings of the One Health concept as the fundamental basis for society's health problems.

\section{The Impact of the Environment on Health}

The quality of life of populations and their health depend on an ecologically balanced environment. The lack of basic sanitation in conjunction with rainfall, floods, urban waste, and a high population density generates large contingents vulnerable to endemic infectious and parasitic diseases [7]. A national policy 


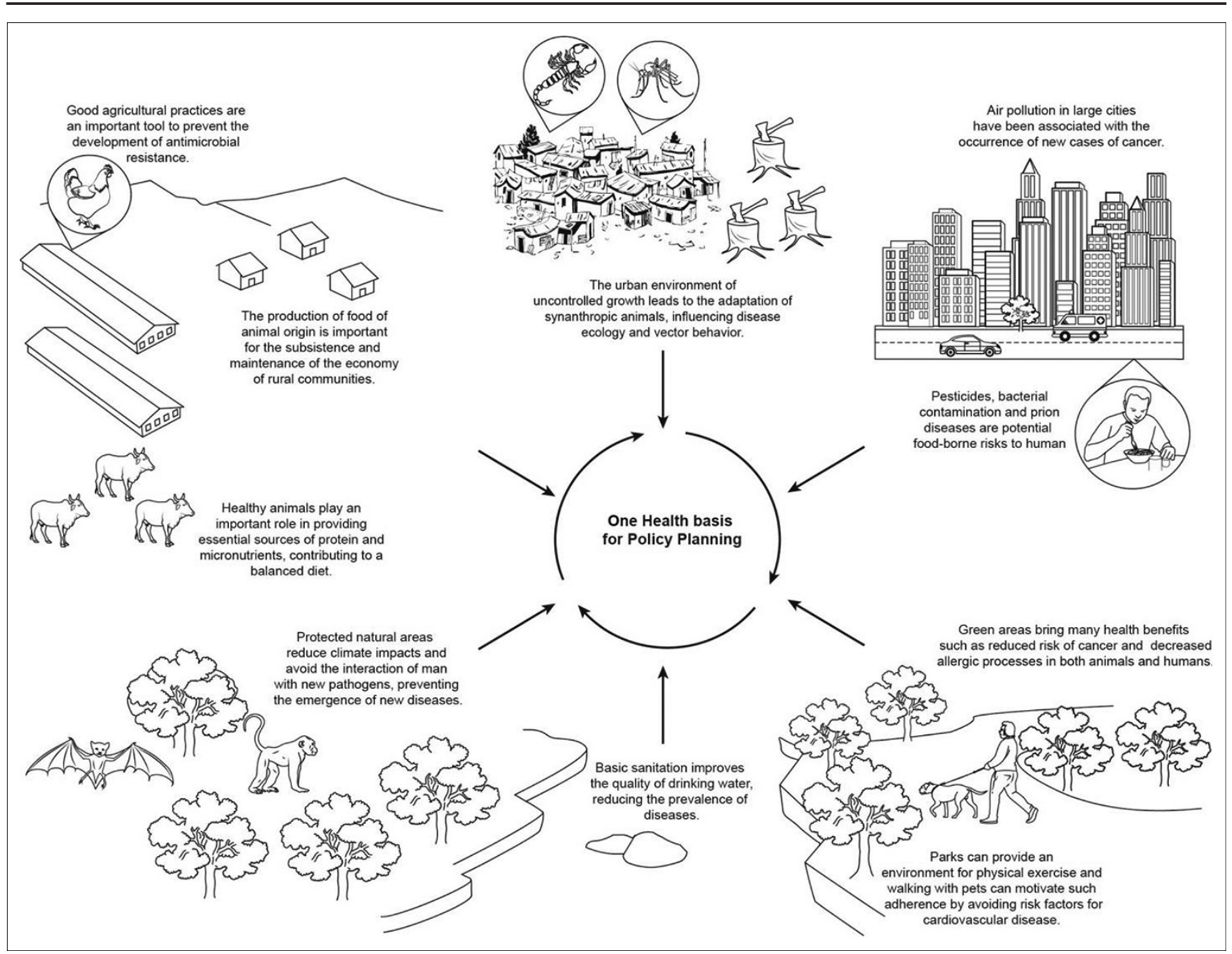

Figure-1: One Health as the fundamental basis for the health problems of society.

designed to improve basic sanitation increases the quality of drinking water and reduces child mortality and the prevalence of these diseases [8].

Zoonoses are typically endemic and occur through natural foci; however, changes in the ecosystem and in the meteorological and climatic conditions can cause epidemics, especially of vector-borne diseases [9]. According to the OIE, more than $60 \%$ of the existing human infectious diseases are zoonoses and three of five human diseases that emerge per year are of animal origin [10], many of them arising from the interaction of humans with still unexplored wild areas.

Human interference with natural areas leads to changes in the biodiversity and density of pathogen hosts [11]. Therefore, the protection of these areas could be a strategy for health promotion in an attempt to prevent the evolution and adaptation of pathogens, whose trends have been defended and have received increasing attention from policy-makers who support a broader, integrated and holistic approach to health [12].

Studies have described important exposure to environmental carcinogens in urban areas with a low presence of green spaces, which might be associated with the occurrence of new cases of cancer [13]. The advantages of natural areas that directly promote human health include a reduction in stress, noise, air pollution, and excessive heat and benefits for the immune system $[14,15]$, as well as the improvement of the health of pregnant women [16]. Furthermore, green areas stimulate the participation in physical activities [17] which, in turn, provide benefits for mental health, reducing, for example, depression through a combination of physiological effects based on improved social interaction [18]. Notably, according to the WHO, non-communicable diseases kill over 36 million people each year, particularly cardiovascular and respiratory diseases commonly associated with physical inactivity [19].

It is interesting to note that the benefits of a balanced environment extend to animal health, demonstrating their inseparability. The mutual presence of allergic symptoms in dogs and humans indicates common underlying causative factors of allergic diseases. Dogs and their owners tend to share their state of health. A green-oriented lifestyle provides an additional barrier to canine and human allergy [20].

\section{Human-animal Interaction}

The human-animal relationship is in fact the ideal topic to illustrate the added value the One Health concept has to offer. Several studies highlight 
the positive effects of animals on the health and well-being of people of all ages and many of them are long-term effects [21], particularly the reduction in stress, blood pressure [22], and depression [23]. Sedentary individuals can be encouraged to practice exercises, with the interaction with animals promoting lifestyle changes [24,25]. In addition, adherence to a physical activity program is a challenge, especially for patients with multiple chronic diseases and the animal might be a motivating factor to adhere to the program $[22,26]$.

Living with pets influences personality variables, the development of empathy $[27,28]$ and social and cognitive skills [29], and strengthens the immune system in children [22]. Other health benefits include those related to animal-assisted interventions. The development, implementation, and evaluation of evidence-based animal-assisted therapy programs can be a powerful addition to conventional treatment and can have significant positive effects on the therapeutic progress and recovery of children and adults. Non-pharmacological approaches to disease management often reduce the costs and harmful side effects of treatments [30,31].

Scientific publications have shown an association between animal abuse and interpersonal violence, and that animal abuse is an indicator of violence against people $[32,33]$. Children exposed to animal abuse are at a higher risk of developing criminal behavior [34]. Within this context, interdependent notification systems that trigger the investigation and intervention in both types of violence, human, and animal, must be encouraged [35]. This approach could contribute to reduce the incidence of crime and violence, particularly domestic violence [36].

Only healthy and mentally stable animals can provide the positive effects cited above. Thus, the One Health approach is a compelling reason to implement public policies for animal welfare and hence for human health [36]. Important public policies are veterinary health care for improving animal health and health education programs to educate people about animal vaccination campaigns, responsible ownership, and reproductive control of stray animals [37].

Within the context of the interaction between human and animal populations, it is important to point out that some species such as rodents, birds, and bats can easily adapt to anthropogenic environments, such as the urban environment of cities, which can be very attractive for the supply of food resources (food waste, pet food, absence of large predators, etc.), acting as reservoirs of zoonotic pathogens $[11,38,39]$. Different risk factors such as poor housing conditions, garbage accumulation, and uncontrolled community growth can further aggravate this situation [40]. In some countries, scorpions have become opportunistic species that cause serious accidents of medical importance [38]. Several other injuries from animal encounters continue to be a public health problem and include bites, stings, and scratches [41]. Parks can serve as a refuge for the protection of species, permitting to keep the balance of these populations. Guided tours can be used to highlight the importance of multiple ecosystems to visitors while allowing to watch potentially dangerous animals in a controlled environment [41].

\section{Animals, Environment, and Food Production}

Foods of animal origin also play an important role in the One Health context since they provide an essential source of proteins and micronutrients and thus contribute to a balanced diet $[8,42]$. Malnutrition affects health and can result in high mortality rates [43]. Despite the high productivity achieved today, many people still experience food insecurity [44].

Food choices link environmental sustainability and human health. The current dietary trajectories are greatly increasing the global incidence of non-communicable diseases, causing significant global impacts of greenhouse gas emissions and contributing to deforestation. There are many alternative dietary options that substantially improve human health and reduce environmental impacts [45]. Land use planning can mitigate some effects of agricultural expansion by preserving remnant natural areas and existing biodiversity and protecting surface waters. The development of new technologies and policies for ecologically sustainable agriculture minimizes impacts and will allow the sufficient supply and equitable distribution of food [44]. The control of animal diseases is a good example of how to increase productivity, reduce the consumption of natural resources, and contribute to decrease the impacts on climate changes [46]. Furthermore, the production of food of animal origin is important for the subsistence and maintenance of the economy of rural communities [47], boosting poverty reduction [46].

Similar challenges are identified regarding the health risks inherent to genetically modified organisms, chemical residues, pesticides, bacterial contamination, and prion diseases, which represent risks to human health transmitted by food [42]. This debate also includes the use of non-therapeutic antibiotics in livestock animals as a tool to increase production efficiency, which is associated with the growing resistance of human pathogens to antibiotics [48]. Antimicrobial resistance causes suffering in the affected patient, human, or animal and has economic consequences because of the increased costs of treatment with social impacts [49]. This fact highlights the need for national policies of antimicrobial resistance surveillance, with the inclusion of animal data and the One Health approach in the topic [50]. In addition, good agricultural practices can be an important tool to prevent the development of antimicrobial resistance, especially for human populations directly exposed to animals [51].

\section{One Health Application for Policy-makers}

The application of the One Health concept to the development and implementation of public policies 
has come with the growing awareness of the need to involve transdisciplinary teams in solving complex problems in response to the challenges of the $21^{\text {st }}$ century and the Sustainable Development Goals. The key to this holistic approach is to establish links and joint actions between the human health, animal, and environmental sectors, involving different actors and institutions, either public or private. The response in one sector must incorporate impact assessment and mitigate adverse effects on downstream sectors, reducing redundancy, and the duplication of policy guidelines [52].

Politics is omnipresent in public health and public policies are a set of government actions that will produce specific effects and influence the lives of citizens, especially on the resolution of problems (Figure-2). The formulation of public policies is the stage in which democratic governments translate their electoral proposals and platforms into programs and actions that will produce results or changes in the real world. This should be based on scientific studies that comprise different areas of knowledge [53]. An integrated approach to policy development improves communication and ensures that the policies developed are relevant and will be accepted and implemented by the concerned parties [5]. We currently observe the fragmentation of interests, programs and health sectors, the lack of participation of society, and professional focus on very limited areas of specialization, the so-called professional silos [54]. The dysfunctionality of the current system emphasizes the need for a structure dedicated to governance of the One Health approach [55], which should be organized into actions, processes, traditions, and institutions by which authority is exercised and decisions are made and implemented so that society can benefit from change [56].
The application of this integration would be what different authors have proposed in relation to the adherence of veterinary services to health services, reducing costs, and increasing acceptance [57]. Some examples of such practices would be human and animal vaccination programs and services and the sharing of transportation and equipment logistics between veterinarians and physicians [58], as well as joint contingency plans for zoonotic epidemic diseases that are essential for success [59] since the control of the disease in humans requires cost-effective actions on animals [60]. Combining cancer registries for dogs and humans may accelerate the detection of environmental cancer risks. The basic idea is that since dogs and humans share the same environment and lifestyle, dogs could be used as an "early warning system" for human exposure as they develop cancer faster than humans due to a shorter life cycle [61].

According to the principle of efficiency, the government must be aware of the evolution of technical knowledge. If the scientific community endorses the idea that the health of the animal (and of the ecosystem) has an umbilical connection with human health, the approach to national public health policies should be no different. Such transdisciplinary approaches can be used both to improve the effectiveness of existing systems and to develop new collective action networks [5]. Science can identify solutions for public health problems but only politics can transform most of these solutions into reality [53].

Strengthening the governance of the One Health approach requires the integration of knowledge to become a key feature of all stages of policy development [62]. In addition, the inclusion of different political actors in the conceptual and planning steps is crucial since it increases appropriation among the

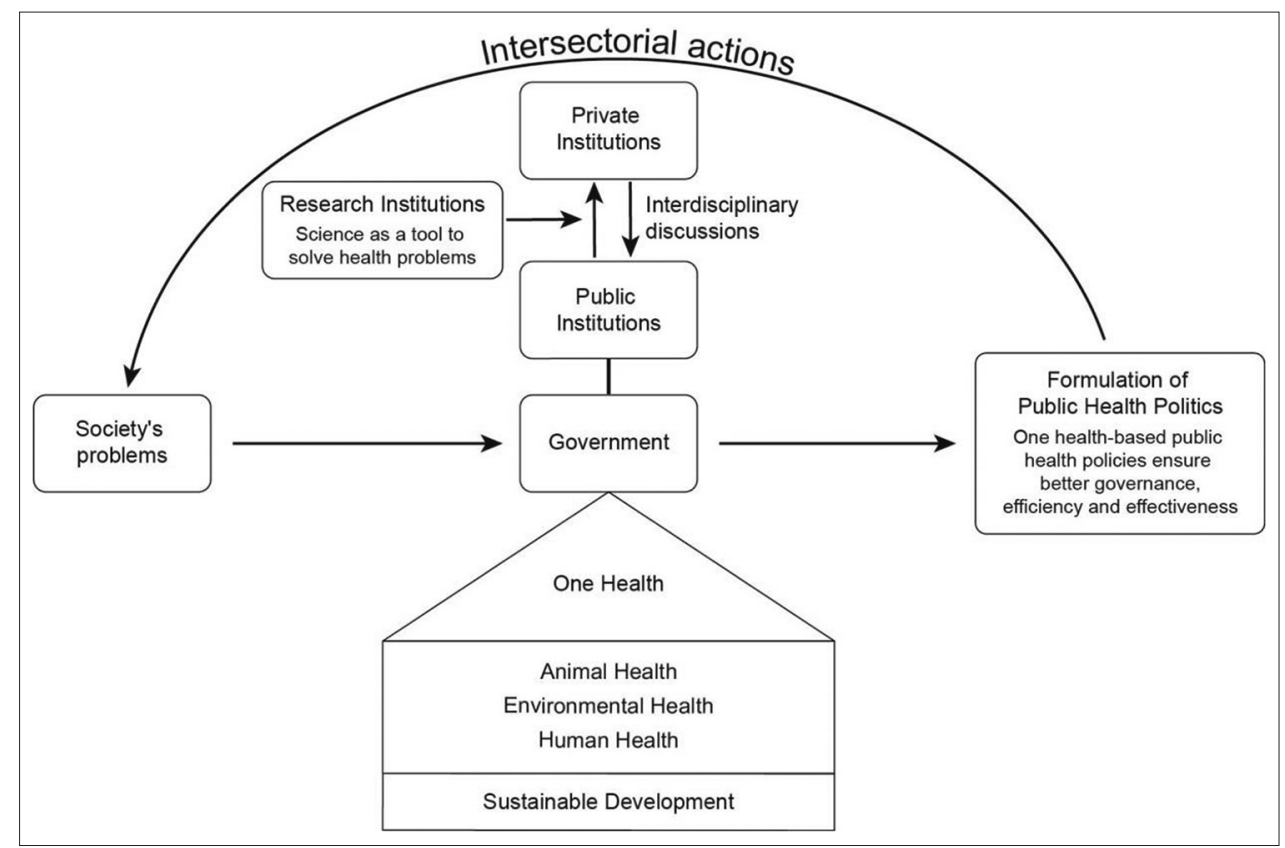

Figure-2: One Health and its supporting pillars for the formulation of public health policies. 
populations and authorities involved, permitting to break down the barriers imposed by the bureaucratic division of responsibility between institutions and even by the organizational culture that limits the dissemination of information $[6,63]$. The recommendation to use One Health as a management tool is achievable through the drafting of laws, protocols, operating procedures, flowcharts, and organization charts, involving government, private sector, and civil society, as well as public policies of local, national, and international scope, including transdisciplinary actions, in addition to technical strategies for mutual and intersectoral cooperation.

Policy-makers should attend to notable/useful early and current $21^{\text {st }}$ century specific One Health literature documentation references chronicled in One Health Initiative(www.onehealthinitiative.com) and One Health Commission (www.onehealthcommission.org) websites, which contain a lot of articles, journals, textbooks, and reports with rich publications to guide One Health approach as a tool.

This study showed how the environment, the interaction of man with animals, food production, and several other factors are linked to human health. These foundations form the pillars of the One Health approach, which underlies the formulation of public health policies for solving the complex problems of the highly globalized modern society and is an acceptable alternative for sustainable development. The holistic view of health, combining the efforts of public, private, and research agencies, will eliminate the existing organizational culture of fragmentation between sectors and political actors, which represents an obstacle to the implementation of integrated and intersectoral policies, ensuring a more efficient public administration and better governance.

We recommend some practical steps with prioritizations: (i) Curriculum guidelines aligned with One Health and sustainable development perspectives in different human resources training courses; (ii) solid legal framework that legitimizes public health practices from the perspective of One Health; (iii) research networks fomentation to assist the implementation of One Health as a public policy; and (iv) organization of working groups and discussion forums between the government, private sector, and civil society to identify public health issues within the scope of One Health.

\section{Conclusion}

This article reveals that most health-related problems involve the same complex, human animals and the environment, so government decision-making should be based on the pillars of the One Health concept, based on the knowledge produced and interconnected by different institutions. public, private and research based on the problems found in society, acting from an intersectoral and multi-professional perspective. Public health policies built from knowledge produced from integrated practice will ensure better governance, since articulated practices guarantee the relevance and acceptability of public health measure.

\section{Authors' Contributions}

RMC and DFB conceptualized this review article. $\mathrm{RMC}$ conducted the bibliography research and prepared the draft. DFB reviewed the text. All authors made intellectual contributions, approving the final manuscript.

\section{Acknowledgments}

We would like to thank Vinícius Orso de Brito for spelling and language checks. Also we would like to thank Coordenação de Aperfeiçoamento de Pessoal de Nível Superior (CAPES) for funding (grant 1560059).

\section{Competing Interests}

The authors declare that they have no competing interests.

\section{Publisher's Note}

Veterinary World (Publisher of International Journal of One Health) remains neutral with regard to jurisdictional claims in published institutional affiliation.

\section{References}

1. Mwangi, W., de Figueiredo, P. and Criscitiello, M.F. (2016) One health: Addressing global challenges at the nexus of human, animal, and environmental health. PLoS Pathog., 12(9): e1005731.

2. World Health Organization. (2019) Taking a Multisectoral, One Health Approach. A Tripartite Guide to Addressing Zoonotic Diseases in Countries. World Health Organization, Food and Agriculture Organization of the United Nations and World Organization for Animal Health, Geneva, Switzerland. Available from: https:// www.oie.int/fileadmin/Home/eng/Media_Center/docs/ EN TripartiteZoonosesGuide_webversion.p $\bar{d} f$. Retrieved on $22-02-2020$.

3. United Nations. (2020) Transforming our World: The 2030 Agenda for Sustainable Development. Available from: https://www.refworld.org/docid/57b6e3e44.html. Retrieved on 22-02-2020.

4. Woods, A. and Bresalier, M. (2014) One health, many histories. Vet. Rec., 174(26): 650-654.

5. Zinsstag, J., Schelling, E., Waltner-Toews, D., Whittaker, M. and Tanner, M. (2015) One Health: The Theory and Practice of Integrated Health Approaches. CABI, Wallingford, United Kingdom.

6. Rüegg, S.R., Häsler, B. and Zinsstag, J. (2018) Integrated Approaches to Health: A Handbook for the Evaluation of One Health. Wageningen Academic Publishers, Wageningen, Netherlands.

7. Lafferty, K.D. (2009) The ecology of climate change and infectious diseases. Ecology, 90(4): 888-900.

8. Bechir, M., Schelling, E., Hamit, M., Tanner, M. and Zinsstag, J. (2012) Parasitic infections, anemia and malnutrition among rural settled and mobile pastoralist mothers and their children in Chad. Ecohealth, 9(2): 122-131.

9. Campbell-Lendrum, D., Manga, L., Bagayoko, M. and Sommerfeld, J. (2015) Climate change and vector-borne diseases: What are the implications for public health research and policy? Philos. Trans. R. Soc. Lond. B Biol. Sci., 370(1665): 20130552.

10. World Organization for Animal Health. (2019) One Health "at a Glance". Available from: http://www.oie.int/en/ 
for-the-media/onehealth. Retrieved on 22-02-2020.

11. Hassell, J.M., Begon, M., Ward, M.J. and Fèvre, E.M. (2017) Urbanization and disease emergence: Dynamics at the wildlife-livestock-human interface. Trends Ecol. Evol., 32(1): 55-67.

12. Jones, K.E., Patel, N.G., Levy, M.A., Storeygard, A., Balk, D., Gittleman, J.L. and Daszak, P. (2008) Global trends in emerging infectious diseases. Nature, 451(7181): 990.

13. Ribeiro, A.G., Baquero, O.S., de Freitas, C.U., Neto, F.C., Cardoso, M.R.A., do Rosario, D.M. and Nardocci, A.C. (2018) Incidence and mortality risk for respiratory tract cancer in the city of São Paulo, Brazil: Bayesian analysis of the association with traffic density. Cancer Epidemiol., 56: 53-59.

14. James, P., Banay, R.F., Hart, J.E. and Laden, F. (2015) A review of the health benefits of greenness. Curr. Epidemiol. Rep., 2(2): 131-142.

15. Li, Q., Morimoto, K., Kobayashi, M., Inagaki, H., Katsumata, M., Hirata, Y., Hirata, K., Suzuki, H., Li, Y.J., Wakayama, Y., Kawada, T., Park, B.J., Ohira, T., Matsui, N., Kagawa, T., Miyazaki, Y. and Krensky, A.M. (2008) Visiting a forest, but not a city, increases human natural killer activity and expression of anti-cancer proteins. Int. $J$. Immunopathol. Pharmacol., 21(1): 117-127.

16. Agay-Shay, K., Peled, A., Crespo, A.V., Peretz, C., Amitai, Y., Linn, S., Friger, M. and Nieuwenhuijsen, M.J. (2014) Green spaces and adverse pregnancy outcomes. Occup. Environ. Med., 71(8): 562-569.

17. Kaczynski, A.T. and Henderson, K.A. (2007) Environmental correlates of physical activity: A review of evidence about parks and recreation. Leis. Sci., 29(4): 315-354.

18. Bauman, A.E, (2004) Updating the evidence that physical activity is good for health: An epidemiological review 2000-2003. J. Sci. Med. Sport, 7(1): 6-19.

19. World Health Organization. (2014) Global Status Report on Noncommunicable Diseases. World Health Organization, Geneva. Available from: https://www.who.int/nmh/publications/ncd-status-report-2014/en. Retrieved on 22-02-2020.

20. Hakanen, E., Lehtimäki, J., Salmela, E., Tiira, K., Anturaniemi, J., Hielm-Björkman, A., Ruokolainen, L. and Lohi, H. (2018) Urban environment predisposes dogs and their owners to allergic symptoms. Sci. Rep., 8(1): 1585.

21. Serpell, J. (1991) Beneficial effects of pet ownership on some aspects of human health and behaviour. J. R. Soc. Med., 84(12): 717-720.

22. Headey, B. and Grabka, M.M. (2007) Pets and human health in Germany and Australia: National longitudinal results. Soc. Indic. Res., 80(2): 297-311.

23. Rieger, G. and Turner, D.C. (1999) How depressive moods affect the behavior of singly living persons toward their cats. Anthrozoos, 12(4): 224-233.

24. Raina, P., Waltner-Toews, D., Bonnett, B., Woodward, C. and Abernathy, T. (1999) Influence of companion animals on the physical and psychological health of older people: An analysis of a one-year longitudinal study. J. Am. Geriatr. Soc., 47(3): 323-329.

25. Wohlfarth, R., Mutschler, B., Beetz, A., Kreuser, F. and Korsten-Reck, U. (2013) Dogs motivate obese children for physical activity: Key elements of a motivational theory of animal-assisted interventions. Front. Psychol., 4: 796.

26. Johnson, R.A. and Meadows, R.L. (2010) Dog-walking: Motivation for adherence to a walking program. Clin. Nurs. Res., 19(4): 387-402.

27. Daly, B. and Morton, L. (2009) Empathic differences in adults as a function of childhood and adult pet ownership and pet type. Anthrozoos, 22(4): 371-382.

28. Poresky, R.H. and Hendrix, C. (1990) Differential effects of pet presence and pet-bonding on young children. Psychol. Rep., 67(1): 51-54.

29. Hergovich, A., Monshi, B., Semmler, G. and Zieglmayer, V. (2002) The effects of the presence of a dog in the classroom. Anthrozoös, 15(1): 37-50.

30. Gilmer, M.J., Baudino, M.N., Tielsch, A.G., Vickers, D.C. and Akard, T.F. (2016) Animal-assisted therapy in pediatric palliative care. Nurs. Clin. North Am., 51(3):381-395.

31. Phung, A., Joyce, C., Ambutas, S., Browning, M., Fogg, L., Christopher, B.A. and Flood, S. (2017) Animal-assisted therapy for inpatient adults. Nursing, 47(1): 63-66.

32. Ascione, F.R. and Shapiro, K. (2009) People and animals, kindness and cruelty: Research directions and policy implications. J. Soc. Issues, 65(3): 569-587.

33. Flynn, C.P. (2011) Examining the links between animal abuse and human violence. Crime Law Soc. Change, 55(5): 453-468.

34. Monsalve, S., Ferreira, F. and Garcia, R. (2017) The connection between animal abuse and interpersonal violence: $\mathrm{A}$ review from the veterinary perspective. Res. Vet. Sci., 114: 18-26.

35. Baquero, O.S., Ferreira, F., Robis, M., Neto, J.S.F. and Onell, J.A. (2018) Bayesian spatial models of the association between interpersonal violence, animal abuse and social vulnerability in São Paulo, Brazil. Prev. Vet. Med., 152: 48-55.

36. Pinillos, R.G., Appleby, M.C., Manteca, X., Scott-Park, F., Smith, C. and Velarde, A. (2016) One welfare a platform for improving human and animal welfare. Vet. Rec., 179(16): 412-413.

37. Kato, M., Yamamoto, H., Inukai, Y. and Kira, S. (2003) Survey of the stray dog population and the health education program on the prevention of dog bites and dog-acquired infections: A comparative study in Nepal and Okayama Prefecture, Japan. Acta Med. Okayama, 57(5): 261-266.

38. Brites-Neto, J. and Duarte, K.M.R. (2015) Modeling of spatial distribution for scorpions of medical importance in the São Paulo State, Brazil. Vet. World, 8(7): 823.

39. Mackenstedt, U., Jenkins, D. and Romig, T. (2015) The role of wildlife in the transmission of parasitic zoonoses in peri-urban and urban areas. Int. J. Parasitol. Parasites Wildl., 4(1): 71-79.

40. Neiderud, C.J. (2015) How urbanization affects the epidemiology of emerging infectious diseases. Infect. Ecol. Epidemiol., 5(1): 27060.

41. Langley, R.L. (2005) Animal-related fatalities in the United States an update. Wilderness Environ. Med., 16(2): 67-74.

42. Nabarro, D. and Wannous, C. (2014) The potential contribution of livestock to food and nutrition security: The application of the one health approach in livestock policy and practice. Rev. Sci. Tech., 33(2): 475-485.

43. Pelletier, D.L. and Frongillo, E.A. (2003) Changes in child survival are strongly associated with changes in malnutrition in developing countries. J. Nutr., 133(1): 107-119.

44. Tilman, D., Fargione, J., Wolff, B., D'antonio, C., Dobson, A., Howarth, R., Schindler, D., Schlesinger, W.H., Simberloff, D. and Swackhamer, D. (2001) Forecasting agriculturally driven global environmental change. Science, 292(5515): 281-284.

45. Tilman, D. and Clark, M. (2014) Global diets link environmental sustainability and human health. Nature, 515(7528): 518 .

46. Pradère, J. (2017) Impact of animal health programmes on poverty reduction and sustainable livestock development. Rev. Sci. Tech., 36(1): 175-193.

47. Bettencourt, E.M.V., Tilman, M., Narciso, V., Carvalho, M.L.D. and Henriques, P.D.D. (2015) The livestock roles in the wellbeing of rural communities of TimorLeste. Rev. Econ. Sociol. Rural, 53(1): 63-80.

48. Casey, J.A., Kim, B.F., Larsen, J., Price, L.B. and Nachman, K.E. (2015) Industrial food animal production and community health. Curr. Environ. Health Rep., 2(3): 259-271.

49. Bengtsson, B. and Greko, C. (2014) Antibiotic resistance consequences for animal health, welfare, and food production. Ups. J. Med. Sci., 119(2): 96-102.

50. Ceric, O., Tyson, G.H., Goodman, L.B., Mitchell, P.K., Zhang, Y., Prarat, M., Cui, J., Peak, L., Scaria, J., Antony, L., Thomas, M., Nemser, S.M., Anderson, R. and Thachil, A.J. 
(2019) Enhancing the one health initiative by using whole-genome sequencing to monitor antimicrobial resistance of animal pathogens: Vet-LIRN collaborative project with veterinary diagnostic laboratories in United States and Canada. BMC Vet. Res., 15(1): 130.

51. Tang, K.L., Caffrey, N.P., Nóbrega, D.B., Cork, S.C., Ronksley, P.E., Barkema, H.W., Polachek, A.J., Ganshorn, H., Sharma, N., Kellner, J.D. and Ghali, W.A. (2017) Restricting the use of antibiotics in food-producing animals and its associations with antibiotic resistance in food-producing animals and human beings: A systematic review and meta-analysis. Lancet Planet Health, 1(8): e316-e27.

52. Chatterjee, P., Kakkar, M. and Chaturvedi, S. (2016) Integrating one health in national health policies of developing countries: India's lost opportunities. Infect. Dis. Poverty, 5(1): 87.

53. Greer, S.L., Bekker, M., De Leeuw, E., Wismar, M., Helderman, J.K. and Ribeiro, S, Stuckler, D. (2017) Policy, politics and public health. Eur. J. Public Health, 27(Suppl 4): 40-43.

54. Galaz, V., Leach, M., Scoones, I. and Stein, C. (2015) The Political Economy of One Health Research and Policy. STEPS Working Paper, No. 81 Brighton: STEPS Centre. Available from: https:/www.opendocs.ids.ac.uk/opendocs/ bitstream/handle/20.500.12413/6598/One-Health-wp3. pdf? sequence $=1 \&$ isAllowed $=y$. Retrieved on 22-02-2020.

55. Lee, K. and Brumme, Z.L. (2012) Operationalizing the One Health approach: The global governance challenges. Health Policy Plan, 28(7): 778-785.

56. Lehnert, T. (2019) Asset pricing implications of good governance. PLoS One, 14(4): e0214930.
57. Schelling, E., Wyss, K., Béchir, M., Moto, D.D. and Zinsstag, J. (2005) Synergy between public health and veterinary services to deliver human and animal health interventions in rural low income settings. BMJ, 331(7527): 1264-1267.

58. Schelling, E., Bechir, M., Ahmed, M.A., Wyss, K., Randolph, T.F. and Zinsstag, J. (2007) Human and animal vaccination delivery to remote nomadic families, Chad. Emerg. Infect. Dis., 13(3): 373.

59. Kelly, T.R., Karesh, W.B., Johnson, C.K., Gilardi, K.V., Anthony, S.J., Goldstein, T., Olson, S.H. and Machalaba, C. (2017) One Health proof of concept: Bringing a transdisciplinary approach to surveillance for zoonotic viruses at the human-wild animal interface. Prev. Vet. Med., 137(Pt B): 112-118.

60. Roth, F., Zinsstag, J., Orkhon, D., Chimed-Ochir, G., Hutton, G., Cosivi, O., Carrin, G. and Otte, J. (2003) Human health benefits from livestock vaccination for brucellosis: Case study. Bull. World Health Organ., 81(12): 867-876.

61. Gavazza, A., Presciuttini, S., Barale, R., Lubas, G. and Gugliucci, B. (2001) Association between canine malignant lymphoma, living in industrial areas, and use of chemicals by dog owners. J. Vet. Intern. Med., 15(3): 190-195.

62. Hitziger, M., Esposito, R., Canali, M., Aragrande, M., Häsler, B. and Rüegg, S.R. (2018) Knowledge integration in One Health policy formulation, implementation and evaluation. Bull. World Health Organ., 96(3): 211.

63. World Bank. (2012) People, pathogens and our planet. In: Towards a One Health Approach for Controlling Zoonotic Diseases. Vol. 1.Washington, DC: The World Bank. Available from: https://www.siteresources.worldbank.org/INTARD/Resources/PPP_Web.pdf. Retrieved on 22-02-2020. 